\section{Uroonian \\ ON THE}

\section{LOCALISATION OF DISEASE.}

DELIVERED BEFORE THE

ROYAL COLLEGE OF PHYSICIANS.

BY

EDWARD H. SIEVEKING, M.D.,

physician to h.r.h. THE PRINCE OF WALES, AND TO ST. Mary's HOSPITAL; PRESIDENT OF THE METROPOLITAN COUNTIES BRANCH OF THE BRITISH MEDICAL ASSOCIATION; ETC.

\section{LECTURE II.}

Mr. President, - I attempted in my first lecture to place before this assembly a series of arguments calculated, if just, to reduce all morbid action to a comparatively simple denomination. I sought to show that the phenomena of disease may all be regarded as those of disturbed nutrition, and that the localisation of morbid action was rather an accidental sequel than the primary and essential feature. Such a theory does away with the distinction between functional and organic disease, because the former necessarily precedes the latter, and the relation of the forms to which the terms are applied is one of degree only. The incongruity of anything like a specific remedy follows equally; because, if we are agreed that disease is some modification of nutrition, our duty is plainly to determine in what the modification consists; and, if we have an adequate knowledge of Nature, the remedy, or, more correctly speaking, the mode of treatment, follows as a matter of course; and, provided the organism be not so far deranged that a dissolution is necessarily at hand, improvement or cure must result. At all events, we fulfil to the utmost the demands that can be made of scientific medicine. I must guard myself against misapprehension in two respects, if my language have failed to convey my exact meaning. We should act upon the same principles that guide the intelligent husbandman, who varies the soil according to the seed that he has to sow, and changes his manure in accordance with the crops that he wishes to gather. I use the term nutrition in a wide sense. It is suppased to embrace the entire process of digestion, with its results, and all those phenomena which are included under the heading of growth and metamorphosis of tissues. I conceive that, with the exception of those diseases which are classed together as zymotic diseases, the primary derangement is essentially one occurring within the body; but that, even when we are bound to believe in the introduction of a poisonous agent from without, its propagation or multiplication depends essentially upon the state of nutrition which prevails in the person attacked. My whole theory is a protest against specifics or empirical treatment, still I have not the presumption to assert that, in the present state of science, we can dispense with empiricism; nor shall I attempt to explain the action of all the remedies that frequent use has compelled us to regard as curative, or at least beneficial, in certain phases of morbid action. I believe that one of the great impediments to the progress of medical science has been that dogmatism which has checked the confession of ignorance; for if we clearly see what we do not know, we are much more likely also to see clearly the field of knowledge that has been opened to us. I do not, indeed, claim remotely to equal many of the distinguished associates of this College in point of abstract knowledge or practical wisdom; and I should not attempt to lay before you a theory which necessarily indicates how little we really do know, did I not rely upon your kind forbearance and consideration, virtues that are generally associated with real greatness of mind. I shall have to throw myself upon your kindness most especially, Mr. President and gentlemen, during the next two Croonian lectures, because I shall wish to establish, by reference to the whole range of medicine, the practical truth of my remarks, as well as the foundation they have in the best and most approved modes of treating morbid action.

My intention during the present lecture is to seek for illustrations of my meaning, not so much in the works of my fellow-labourers as in the still greater Book of Nature. If I draw upon the former, it will be mainly because they appear to me to have delineated Nature's workings in disease better than I can, not because I desire the authority of great names to bolster up an hypothesis. I believe that, in this matter, I am actuated solely by the desire to approach nearer to that goal which all of us-and who more zealously than the gifted and beloved president of the Royal College of Physicians of London?-run that we may attain, truth.

If any one should be disposed to raise the cui bonro objection to the whole intent of the argument, I would submit this consideration. If local disease be the expression of antecedent derangement, clearly the recognition of this condition will be a benefit to the individual no less than to our race, varying in its importance with the danger of the malady:* It is in accordance both with reason and experience that, as a seed is more readily crushed or destroyed than the tree which springs from it, so the morbid conditions of our frame will be checked and eradicated with the greater ease, the earlier we are enabled to attack and arrest their development. There are many diseases, an early recognition of which the present state of medicine does not enable us to arrest them with certainty; that may be due either to the fact of our not possessing the proper antidote, or to our failing in making our diagnosis at a sufficiently early period. But a present failure, from whatever cause, does not in itself invalidate any fact bearing upon the development and history of disease; this rests upon its own basis. Besides, if my conclusions are legitimate, they tend to prove that we are far from using or even possessing all the means necessary for the earliest detection of perverted nutrition, perverted secretion, perverted metamorphosis of tissue. The fall of the barometer indicates with certainty the coming hurricane; but it does not tell us whether the mariner has the ability to sail his ship, or whether the ribs and spars of the ship possess the strength that will enable her to weather the storm. What is required in medicine is a similar certainty of anticipating the future-of prophesying the course of morbid events; and the further back we are able to

* I would wish to draw the reader's attention specially to an admirable paper published in the last volume of Guy's Hospital Reports, in which Dr. Wilks handles the question of lucal disease from the pathological point of view, and which, unfortunately, has only come under my notice as this lecture was passing through the press. 
trace the changes that eventuate in disease, by means independent of any statements of the patients, the more completely shall we be able to delineate their future course, or the more precisely shall we apply the agents suitable for particular manifestations or stages of morbid phenomena.*

Allow me to ask your attention to a common cold, not more frequently regarded as the starting point of serious disease than it merits, according to our prevailing nosology, and yet, I believe, more uniformly still the consequence of earlier unrecognised, but still very often traceable, derangements. You will find little or nothing on the subject in the great works on medicine that we regard as our main instructors. What is a cold? The erkältung of the Germans, the refroidissement of the French, go more to the root of the matter, and convey the fact that, in consequence of cold, something has been deprived of its normal temperature. This physical fact is undoubtedly an exciting cause of the cold; but we are constantly exposed to great varieties of temperature, and parts of our bodies suffer from a refroidissement, and still we do not catch cold. How, then, is the cold to be accounted for? If we examine carefully into the history of a cold, we may generally discover that circumstances have preceded, in which a due elimination of the products of respiration or of other volatile excreta have been interfered with. The real failure of health takes place from the moment when the eudiometric condition of a locality in which we are, prevents the due discharge of watery vapour and carbonic acid from our lungs and skin; and the greater the consequent accumulation of effete matter within the system - may we not fairly say, within the vascular system?-the less shall we be able to bear sudden alternations of temperature. The young lady, who catches cold in going out of a suffocating London ball-room, has during a few hours been doing her best to store up in her body a large quantity of wasted tissue which ought to have been removed, burnt off, by even a larger supply of air than that which suffices when she is engaged in the less exciting calls of morning tuition. The physician who dines with an hospitable confrère, in a room in which the available oxygen is consumed before the soup is removed, not only accumulates in his stomach more viands than he can digest at the time, but is quite incapable of throwing off the amount of carbonic acid necessary to health, and necessarily catches cold as he leaves the house or suffers from its analogues on the following day. The rowing man or the cricketer do not catch cold, although the consumption of tissue may be still greater while they are actively occupied in their respective pursuits, because they are carried on in the open air. They are obeying a law of Nature which tells the young as it tells us all, that it is good to accelerate the metamorphosis of the tissues of the body in order to make room for fresh and vigorous growth; but they would be obeying?it

\footnotetext{
- In a recent address, Professor Owen, in discussing the claims of medicine to be regarded as a science, illustrates his position by the hold that chemistry and astronomy have upon the public mind as compared with the regard formerly shewn to alchemy and astro. logy, and states that the power of prophesy is essentially that quality which impresses the public. "It is interesting," he remarks, "to consider how a public, ignorant of and careless about the grounds and proofs of an established scieuce, does in time come to believe in and trust it, to the exclusion of its simulacra, and the utter deposition and extinction of the quack professors of the sanne. I believe the public gain this fuith by what the true science effects, and what it predict8." (Britisit Medical JovanaL, June 10th, 1865.)
}

only in a very imperfect manner if their sports were not fanned by the breezes of heaven, for the worn out tissues would remain in the body and become a clog and a poison, instead of being a source of renewed health. The local affection of the catarrh, the subinflammatory condition of the mucous membrane of the antrum Highmorii, the posterior and anterior nares, which causes so much annoyance, must only be regarded as a sign of the previous derangement. Whether, as is often asserted, the disease is an " effort of Nature" to throw off an injury, may or may not be true. We know that Nature is often a long time in affecting this, and that the patient not unfrequently succumbs during the process; we also know that, the earlier we can trace a morbid taint, the more readily we can aid Nature in her attempts to remove it and restore the patient to his normal condition. If the power of prophesying is, according to Professor Owen, the test of science, we could easily show that the powers possessed by the scientific physician are greater than usually admitted. He can foretell with certainty, if he knows the materials he has to deal with, or, in other words, the condition of his patient and the influences he will be subject to, what the result will be-the chemist can do no more. We act upon this knowledge in daily life; but the effect of the prophesy is often concealed or the warning not listened to, because we have to deal with responsible beings, and not with inanimate matter contained in a test-tube. Let us now see whether the same kind of argument that I have sought to illustrate by what takes place in the production of a common cold is applicable to more serious diseases. Can we trace in them that harmonious operation of the laws laid down by an allwise Creator? or must we regard them as manifestations of His power, destined solely to point some moral discourse of fatalistic tendency?

I will first sketch a case of pneumonia, of which I take the headings from my note-book. I do not, in doing so, mean to imply that all inflammations of the lung-tissue are brought about in the same manner. I see endless variety both in the causation and the phenomena of disease, though with all everywhere the same fundamental laws. It is this constant variety that compels me to doubt the wisdom of those who would adopt one mode of treatment for any disease, merely because nosologists have classified certain physicial signs under the samenames. Whether the inferences that I shall draw from one or two isolated cases of pneumonia are more generally applicable to the causation of what is called idiopathic disease, is just one of those questions that we are here to discuss; but, while $\mathbf{I}$ protest against our being bound by an artificial nosology, I would maintain that there is a certain unity in the laws that govern disease as there is in those that preside over health.

A. B. is a gentleman of independent means, who has always enjoyed excellent health, and has been engaged in out-of-door occupations, until, at sixty years of age, in consequence of a portion of a step giving way, he has a severe fall bruising his hip considerably. The injury, though not very serious, confines him to his room for some weeks. Before he has recovered his previous active habits, he goes out on a cold raw day, in consequence of which he suffers from flying pains passing from one side of the thorax to the other, and regarded as gouty neuralgia 
by the medical attendant. The prostration, however, and symptoms of general exhaustion, indicate more serious mischief ; and on closer examination, we detect dulness and crepitus at the base of one lung; and, after a few days, the same symptoms indicate, although there is scarcely a trace of cough or expectoration, that the other lung is similarly affected. As there is no albumen in the urine and no heart-disease or other complication, rest and alterative medicines and derivatives, followed by a tonic regime and medication, slowly but surely restore our patient to health. Resolution takes place, and the ordinary rotation of healthy phenomena is able to resume its course.

In this case, we have an illustration of what Mr. Erichsen and Mr. Hilton have so well described as occurring frequently after injuries. The absence of due exercise prevents due aëration of blood; and, an undue amount of waste tissue having to be burnt off, the lungs are more highly taxed than their opportunities allow them to accomplish-and disease sets in, in the local form of inflammation of the lungtissue. It is an expression, however, of long antecedent general malnutrition. Or take another case, which is not so uncomplicated as the last.

C. D., a government official, has a syphilitic sore in the course of the summer, followed by roseola and other secondary symptoms. In consequence of exposure during a voyage, he is seized with intense pain in the left side, which is called pleurisy; and this is followed by indefinite pains, apparently of a rheumatic character, affecting different parts of the trunk. There is some cough and expectoration, once streaked with blood. On examination of the chest, about six weeks from the time when he was seized with the stitch in the side, percussion and the stethoscope reveal a subacute pneumonia at both bases, as shown by the presence of dulness, bronchial respiration and dry crepitation. The almost entire absence of all febrile symptoms-in fact, of any symptoms except great debility and prostration and rheumatic pains-might in such a case easily mislead the observer, were it not for the stethoscope and physical exploration. But, having made your diagnosis of pneumonia, would it be possible to regard this in any other light than as the reflex of the antecedent morbid conditions fixed in the lung by the casual interference with the aërating process, while there was accumulated material for destruction and removal in the pulmonary furnace? It would not have been difficult for a well-instructed physician to prophesy the result. What else is the meaning of the warning so constantly urged, that during convalescence from other affections exposure should be avoided, because there is at that time a peculiar liability to an interference with the regular metamorphosis-the waste and repair of the tissues-and therefore a peculiar proclivity to catching cold?

The difference in the severity of pneumonia in different subjects could doubtless be sufficiently accounted for were we sufficiently acquainted with the details of their mode of living, and were it possible to put all the different elements of health or disease into the balance. The examination of the excreta is one of the means by which, in a retrograde manner, we get at the internal organs and their functions, and thus indirectly at the state of the blood; but after they are eliminated they are no longer a part of the individual, and their analysis is not, and cannot be, a direct analysis of a vital process. The test-tube and the microscope are apt to mislead us into the belief that we are watching disease itself ; they enable us to examine the products of morbid action only. The pulse and the tongue and other media give us a clue to vital processes, and have therefore always, and justly, been esteemed by the practical man as the true indications of disease; but their variability under non-essential influences often diminishes their value-so that the physician readily hails any new and positive mode of measuring internal processes, which is not amenable to any subjective impression of the patient. We may hope to have re-discovered such a method in the employment of the thermometer-an instrument which, as we are told by high authority, greatly facilitates the clinical recognition of diseases, while it tends to elucidate the natural history of all diseases where fever is present.* My personal acquaintance with the use of the thermometer in disease is only sufficient to enable me to bear feeble testimony to its value; but I am disposed to anticipate its utility in the still wider range of prophesy, to which I conceive it will become an efficient handmaid-prophesy of future events by the positive present recognition of minute changes scarcely perceptible to the individual in whom they occur, and certainly not measurable by another, unless aided by so trustworthy but delicate an indicator as a well made thermometer. Dr. Aitken tells us that all observers, Valentin and Traube in Germany, Edwards, Becquerel, Breschet, and Bernard in France, and Dr. John Davy in England, are agreed with regard to the fluctuations in health so as to afford us a standard of comparison in disease. Seeing how close are the relations between animal heat, pulse, and respiration, and how important the accurate knowledge of these functions is in reference to any variations in health or deviations from the normal standard, the thermometer, as a means of determining accurately one of these three elements, becomes a mighty lever of science. It appears that, in temperate regions, the normal temperature at completely sheltered parts of the surface of the human body amounts to $98.4^{\circ}$ Fahrenheit, or a few tenths more or less, and a rising above $99.5^{\circ}$ Fahrenheit or a depression below $97.3^{\circ}$ Fahrenheit are sure signs of some kind of disease, if the increase or depression is persistent. The large experience of Wunderlich has enabled him to speak most positively as to the value of this instrument in detecting ana' following up morbid changes. He has already given numerous instances, showing how by the thermometer disease was indicated before any other means of diagnosis availed for that purpose. Elevation of temperature is generally associated with disordered functions perceptible to the individual in whom they occur, as well as to the bystander; but it may even amount to four or five degrees, and still coincide with a quiet pulse.and apparent health. (New Sydenham Society's YearBook, 1861, p. 119.) It is this certa inty with which it indicates hidden processes, which induces me to hope that further study will enable us to foretell events with yet greater certainty than we possess at present, and that it will prove one of the means by

* Upon these and all matters connected with the most recent advances in medical science, the En glish language affords no better information than that given in the fourth edition of Dr. Aitken's Science and Practice of Medicine, 1865, loc. cit., vol. i, p. 38; see also New Sydenham Society's Year-Fsooks for 1861-62. 
which we may detect the earliest deviations of function from the healthy standard. In the particular disease which we have been considering, it has been shown to give more certain proof of definite changes or of the absence of certain variations in the course of the malady than any other means at our disposal. A temperature of $104^{\circ}$ and above is a sign of grave import in pneumonia. (New Sydenham Society's Year-Book, 1862, p. 176.) In genuine pneumonia, the temperature is stated to rise rapidly, amounting on the first day to $101.7^{\circ} \mathrm{Fahrenheit}$, and maintaining a temperature of $4.5^{\circ}$ to $5.6^{\circ}$ above the normal standard, with little or no morning remission; on the fifth or seventh day it falls rapidly; and in thirtysix hours returns to the natural condition. Peculiar variations of temperature in the course of the disease are described as characteristic of definite varieties of pneumonia. To conclude this digression, Wunderlich affirms generally that the temperature is the surest measure of the improvement or aggravation of a disease, of its running a favourable or unfavourable course, and of the efficacy of treatment. I may add that in surgery this little instrument has also been employed with advantage, both in determining the presence or absence of traumatic fever and in fixing the exact local changes in deep-seated tissues.

The theory which I have advocated, that pneumonia is not a disease per se, but the climax of a series of antecedent morbid changes would be liable to contradiction, so long as we have not obtained positive proof of the deranged condition of the blood and of the nutrition generally. I have sought to indicate the general grounds deducible from what is observed in individual cases. Other evidence, though not absolutely conclusive, appears to be given in the admitted hyperinosis of the blood before the outbreak of pneumonia and the diminution of the general symptoms of disease as those of the local affection become more prominent. However, so long as the direct evidence is not obtainable, we must be allowed to have recourse to circumstantial evidence, and be satisfied to use 'such means of observation as are now at our dispos.t.

I trust that I ma not be misunderstood as maintaining the imposibility of any form of pneumonia without an arrested or perverted metamorphosis of the tissues. The pneumonia occurring in the course of trichiniasis; is one of those rare forms that are attributable tn the presence of a direct irritant in the lung-tissue. The pneumonia, so fatal in some trades, in which mechanical irritants find an entrance into the lungs, belong to the same category. But they are not the pneumonias of every-day life ; and it is to the ordinary cases of inflammation of the lung-tissue which we meet with in hospital and private practice, that my reinarks apply.

[To be continued.]

Accidents IN the Metropolis. The number of persons run over and killed in the streets of the metropolis during last year was 140 . In the same year 1707 persons were injured. To the end of February in the present year 23 persons were killed and 231 injured from the same causes. In the City Police district last year. 14 persons were killed in the streets and 207 injured. In the same district up to Feb. 26 of the present year 8 were killed and 30 injured.

\section{Ariginal Commanications.}

\author{
ON THE CAUSES WHICH TEND TO AND \\ OCCASIONALLY ENDANGER FETAL \\ LIFE DURING LABOUR:
}

WITH REMARKS ON SOME OF THEIR MEDICO-LEGAL BEARINGS.

By G. K. H. Paterson, L.R.C.P.Ed., L.R.C.S., Balbeggie, Perthshire.

[Read before the Perthshire Medical Association.] [Continucd from page 145.]

IT is well known that the states mentioned in my previous paper lead to, and frequently cause, stillbirth. However, according to the recent Report of the Capital Punishment Commission, several alterations in the present law in reference to crime are advised to be made; and one particularly relating to my subject is felt by not a few in the profession to be rather startling, and is consequently of great interest, and vitally important in a medico-legal point of view. I refer to the recommendation of the aforesaid Commission in regard to infanticide ; viz, "that it should be made an offence punishable, etc., maliciously to inflict injury on a child during its birth, or within seven days afterwards, in case the child should have subsequently died; and no proof that the child was completely born alive should be required." On such becoming a part of the future criminal code of our country, difficulties from conflicting medical opinion will, to my thinking, be found to occur from time to time in several ways. But it is necessary to show how such can arise. It will be admitted as far from being uncommon, that, in a case of difficult labour, with no medical attendant present at the time, the child may die during labour or before its complete birth, and may also present appearances not unlike "inflicted injury"; while nothing could be discovered to implicate the mother. Let me state the following possible cases.

A woman, in broad daylight and alone in her own house, is all of a sudden taken in labour at the full term. The head of the child protrudes; it is heard by her to cry, and more so when the head is extruded. It remains in this-often dangerous-position until the next uterine pain, which perhaps does not come on for five or ten minutes after. Meanwhile, she tries with one of her hands to push forcibly the child's head, so as to relieve herself until gradually its body comes into the world. In doing this, her nails have pierced parts of the head, neck, and face of it. At length it is completely born, and found to be lifeless.

Place alongside of this case a woman taken up for concealed birth. Her child is found soon afterwards hidden in the room in which she bore it, with severe scratches here and there on parts of its neck and head, etc.; while the mother afterwards confesses that she heard it cry shortly before it was completely born, and did the same thing as the previous one to aid selfdelivery, and with an unfavourable termination.

In another case, the child's head being similarly extruded, and shewing many signs of fotal life, the mother, from some inhuman motive, stuffs its mouth with a part of either her flannel petticoat or a corner of the bedsheet, and afterwards declares that it was stillborn.

How is the first of these to be exonerated from blame, and the second or the third to be convicted 